\title{
Revalidation and redescription of Triatoma brasiliensis macromelasoma Galvão, 1956 and an identification key for the Triatoma brasiliensis complex (Hemiptera: Reduviidae: Triatominae)
}

\author{
Jane Costa ${ }^{1}{ }^{+}$, Nathália Cordeiro Correia ${ }^{1}$, Vanessa Lima Neiva ${ }^{1}$, \\ Teresa Cristina Monte Gonçalves ${ }^{2}$, Márcio Felix ${ }^{1}$ \\ ${ }^{1}$ Laboratório de Biodiversidade Entomológica 2 Laboratório de Transmissores de Leishmanioses, \\ Setor de Entomologia Médica e Forense, Instituto Oswaldo Cruz-Fiocruz, Rio de Janeiro, RJ, Brasil
}

\begin{abstract}
Triatoma brasiliensis macromelasoma is revalidated based on the results of previous multidisciplinary studies on the Triatoma brasiliensis complex, consisting of crossing experiments and morphological, biological, ecological and molecular analyses. These taxonomic tools showed the closest relationship between T. b. macromelasoma and Triatoma brasiliensis brasiliensis. T. b. macromelasoma is redescribed based on specimens collected in the type locality and specimens from a Fl colony. The complex now comprises T. b. brasiliensis, T. b. macromelasoma, Triatoma melanica, Triatoma juazeirensis and Triatoma sherlocki. An identification key for all members of the complex is presented. This detailed comparative study of the morphological features of $\mathrm{T}$. b. macromelasoma and the remaining members of the complex corroborates results from multidisciplinary analyses, suggesting that the subspecific status is applicable. This subspecies can be distinguished by the following combination of features: a pronotum with 1+1 narrow brownish-yellow stripes on the submedian carinae, not attaining its apex, hemelytra with membrane cells darkened on the central portion and legs with an incomplete brownish-yellow ring on the apical half of the femora. Because the T. brasiliensis complex is of distinct epidemiological importance throughout its geographic distribution, a precise identification of its five members is important for monitoring and controlling actions against Chagas disease transmission.
\end{abstract}

Key words: Brazil - Chagas disease vector - Heteroptera - kissing bug - morphology - taxonomy

Chagas disease is an anthropozoonosis caused by the protozoan parasite Trypanosoma cruzi, which is mainly transmitted by haematophagous bugs of the subfamily Triatominae (Hemiptera: Heteroptera: Reduviidae), which contains 137 registered valid species (Galvão et al. 2003). Following this work, a few species were added and, currently, 147 species are included in the group (Forero et al. 2004, Poinar 2005, Costa et al. 2006, Galvão \& Angulo 2006, Bérenger \& Blanchet 2007, Costa \& Felix 2007, Martinez et al. 2007, Sandoval et al. 2007, Jurberg et al. 2009, Rosa et al. 2012, Gonçalves et al. 2013).

Triatoma brasiliensis Neiva, 1911 is currently the main Chagas disease vector in the semiarid areas of northeastern Brazil (Silveira \& Vinhaes 1999, Costa et al. 2003a) and was originally described from the municipality of Caicó, state of Rio Grande do Norte (RN). Neiva and Lent described a different chromatic form of T. brasiliensis from Espinosa, state of Minas Gerais (MG), as subspecies Triatoma brasiliensis melanica Neiva \& Lent, 1941. Therefore, the nominotypical subspecies Triatoma brasiliensis brasiliensis Neiva, 1911 was established.

doi: $10.1590 / 0074-0276108062013016$

Financial support: $\mathrm{CNPq}$

+ Corresponding author: jcosta@ioc.fiocruz.br

Received 13 December 2012

Accepted 22 February 2013
Galvão (1956), based on specimens from the municipalities of Petrolina [state of Pernambuco (PE)] and $\mathrm{Cu}-$ raçá [state of Bahia (BA)], illustrated and characterised a new subspecies in a taxonomic key: Triatoma brasiliensis macromelasoma Galvão, 1956. Later, Lent and Wygodzinsky (1979) suggested a synonymy to the subspecies of $T$. brasiliensis, stating that intermediate forms could be found in nature.

Several field captures were then carried out throughout the geographic region of the T. brasiliensis complex from 1994-2002. Approximately 2,060 specimens were compared according to their chromatic patterns and geographic distribution. A characteristic darker colour pattern was found in specimens from BA. Multidisciplinary studies were carried out to analyse the distinct $T$. brasiliensis morphotypes based on their morphology (Costa et al. 1997a, 2009), biology (Costa \& Marchon-Silva 1998), ecology (Costa et al. 1998, 2002) and isoenzymatic profile (Costa et al. 1997b), as well as crossing experiments (Costa et al. 2003b) and sequence analyses of the cytochrome $b$ gene fragments from their mitochondrial DNA (mtDNA) (Monteiro et al. 2004); these studies confirmed the existence of a species complex.

The molecular studies and crossing experiments were decisive to the elevation of T. b. melanica to species status (Costa et al. 2006) and to the description of the new species Triatoma juazeirensis Costa and Felix 2007, both identified as independent evolutionary units. Recently, phylogenetic studies using cytochrome $b$ and $16 \mathrm{~S}$ rRNA sequencing identified Triatoma sherlocki Papa et 
al. 2002 as a sister species of T. melanica and a member of the T. brasiliensis complex (Mendonça et al. 2009). These studies also suggest that $T$. b. brasiliensis and $T$. b. macromelasoma are sufficiently distinct from other members of the group and thus, their subspecies status requires revalidation.

In this paper, we provide a detailed redescription of $T$. b. macromelasoma, mainly following the characteristics proposed by Lent and Wygodzinsky (1979) for the Triatominae group. Its subspecies status, as well as that of T. b. brasiliensis, is revalidated based on a morphological comparative study of all members of the T. brasiliensis complex, which corroborates the results from the above cited multidisciplinary approaches. An identification key for all members of the complex is also provided.

\section{MATERIALS AND METHODS}

The material studied herein is deposited in the Entomological Collection of Oswaldo Cruz Institute (CEIOC), Oswaldo Cruz Foundation, Rio de Janeiro, Brazil. The type specimens of T. b. macromelasoma and T. melanica have been lost; therefore, these specimens were identified based on the literature and on comparisons with previously determined material deposited in the CEIOC, including the holotypes of T. juazeirensis (Costa \& Felix 2007) and T. brasiliensis (Gonçalves et al. 1993).

The redescription of T. b. macromelasoma is based on two specimens from its type locality (municipality of Petrolina, PE), as well as 15 males and 15 females from an F1 colony reared from insects collected in this locality.

The manner of description and morphological terminology mainly follow the style of Lent and Wygodzinsky (1979). Measurements were taken using a stereoscopic microscope with an ocular micrometre.

\section{RESULTS}

T. b. macromelasoma Galvão, 1956, revalidated (Fig. 1)

T. b. macromelasoma Galvão (1956)

T. brasiliensis Lent and Wygodzinsky (1979)

Length: males 19.4-24.3 mm, females 21.5-25.5 mm; width of pronotum (posterior lobe): males 3.9-5.4 mm, females 4.4-5.3 mm; width of abdomen: males 6.0-7.6 $\mathrm{mm}$, females $6.6-9.1 \mathrm{~mm}$. All measurements are listed in the Table.

Overall colour: dark brown with yellow to brownishyellow marks.

Head: dark brown. Twice as long as wide across the eyes (males 1:0.35-0.42; females 1:0.35-0.41) and distinctly longer than the pronotum (males 1:0.70-0.86; females 1:0.72-0.89). Anteocular region four times as long as postocular (1:0.25). Clypeus distinctly, but not abruptly widened behind the middle. Genae tapering distally, but with apex narrowly rounded, not pointed, slightly projecting beyond the level of the apex of clypeus. Jugae widely rounded apically. Eyes, in lateral view, approaching, but not attaining the level of the under surface and remote from the level of the upper surface of the head. Ratio width of eye to synthlipsis 1:2.00-2.30 (males) and 1:1.91-2.67 (females). Antenniferous tubercles inserted slightly before middle of anteocular region. First antennal segment attaining the level of the apex of clypeus; second segment subcylindrical, beset with declivous setae shorter than diameter of the segment. Ratio of antennal segments 1:4.0-5.3:2.4-3.8:2.0-2.8 (males) and 1:3.4-4 $.5: 2.4-3.2: 2.0-2.8$ (females). Rostrum thick, as dark as the head capsule, with medium-sized hairs on the first and on the underside of the second segment, with long and very numerous hairs on the upper surface of the second and on the entire third segment; hairs especially dense dorsally at the junction of the second and third segments. First rostral segment extending to the level of the apex of antenniferous tubercles, second one to the level of the apex of the middle of the eyes. Ratio of rostral segments 1:1.9-2.7:1.1-1.4 (males) and 1:2.1-2.3:1.1-1.3 (females). Neck dark, with a pair of light-coloured spots laterally.

Pronotum: very sparsely granulose. Dark brown. Anterior lobe with distal brownish-yellow tubercles. Posterior lobe with submedian carinae evanescent on posterior fourth; 1+1 narrow brownish-yellow stripes on carinae broadening posteriorly, not attaining pronotal apex. Humeral angles rounded, slightly angular. Scutellum: black, posterior process with small yellow or brownish-yellow point on apex. Scutellum coarsely
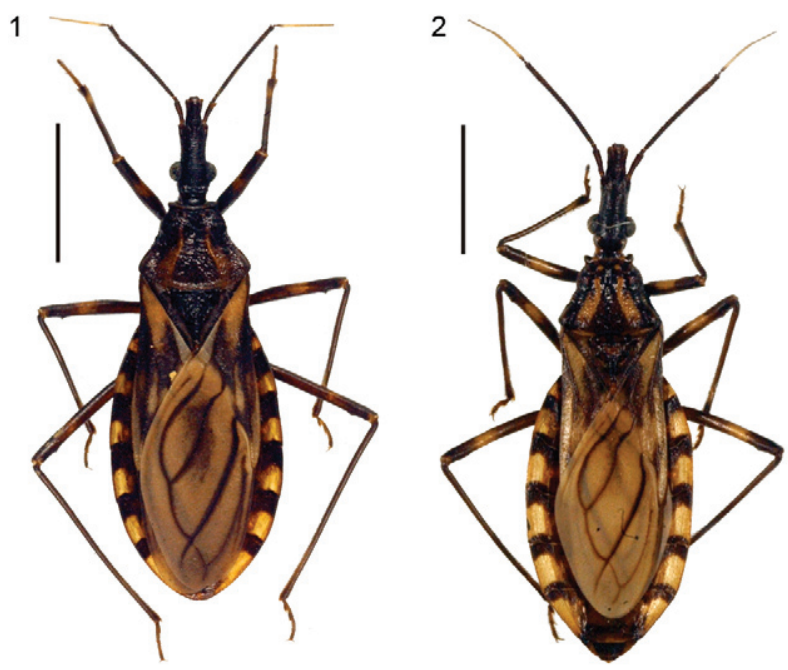

3

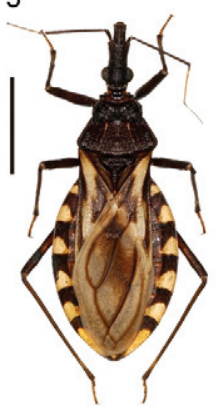

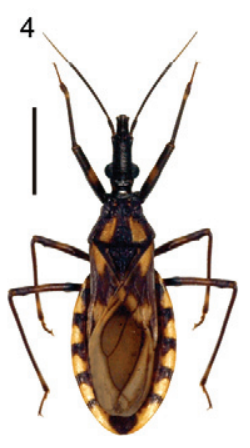

5

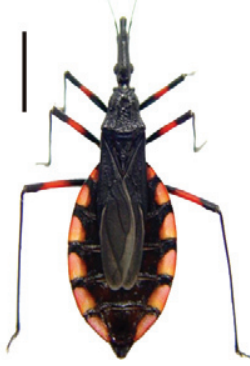

Figs 1-5: the five members of the Triatoma brasiliensis species complex, dorsal habitus. 1: Triatoma brasiliensis macromelasoma, male; 2: Triatoma brasiliensis brasiliensis, female; 3: Triatoma juazeirensis, male; 4: Triatoma melanica, male; 5: Triatoma sherlocki, female. Bars $=5 \mathrm{~mm}$. 
wrinkled, with or without a distinct central depression. Posterior process as long as the main body of the scutellum, subcylindrical, but slightly compressed laterally; apex slightly elevated, rounded.

Hemelytra: extending to variable levels from the base to the apex of the seventh urotergite. Corium light yellow, with dark areas of variable extension, mainly in veins $\mathrm{Cu}, \mathrm{m}-\mathrm{cu}$ and $\mathrm{R}+\mathrm{M}$, attaining Sc. Clavus entirely dark. Membrane fumose, yellowish-brown, as light as light-coloured areas of corium. Veins of membrane black; lumen of cells with a more or less extensive, irregularly shaped sooty spot extending over the central portion, mainly extending to the $\mathrm{Cu}$ and Pcu veins.

Legs: dark, with light markings on the trochantera; incomplete brownish-yellow ring on the apical half of the femora and the subapical portion of the tibiae. Legs slender, fore femora six-seven times as long as wide. Fore and mid femora salient below subapically or with one or two weak denticles. Males with spongy fossulae on tibiae of fore and mid legs; absent in females.

Abdomen: slightly flattened below in both sexes, delicately striate transversally, sparsely setose. Spiracles adjoining connexival suture. Abdomen of female very wide, lateral portions of urotergites exposed. Venter brown; spiracles enclosed in minute yellow area. Connexival segments presenting a black spot on anterior region, posterior edge rounded, followed by a larger light yellow spot; wide black spot enclosing intersegmental sutures.

Male genitalia: as described by Lent and Jurberg (1978) [according to Costa et al. (1997a), individual variations in the male genitalia of T. brasiliensis and the other members of the complex are not correlated with their different and stable chromatic forms. Therefore, the genital structures are not useful for distinguishing T. b. macromelasoma.].

Material examined - T. b. macromelasoma - PE: two males, Petrolina, CEIOC; 15 males, 15 females, F1 colony reared from insects from Petrolina, CEIOC. $T$. b. brasiliensis - RN: one female (holotype), Caicó, CEIOC; state of Ceará: five males, five females, Jaguaruana, CEIOC. T. juazeirensis - BA: one female (holotype), three males (paratypes), two females (paratypes), Juazeiro, CEIOC; seven males, 12 females, Juazeiro, CEIOC. T. melanica - MG: three males, three females, Espinosa, CEIOC. T. sherlocki - BA: one male, one female, Gentio do Ouro, CEIOC.

\section{Key to $T$. brasiliensis complex}

1a. Brachypterous specimens, hemelytra not extending posteriorly beyond the posterior margin of urotergite VI; legs unusually long; ground colour dark brown to black, connexivum and femora with orange to red marks T. sherlocki (Fig. 5) (BA)

1b. Macropterous specimens, hemelytra extending posteriorly at least as far as urotergite VII; legs normally long; ground colour brown, hemelytra and connexivum with brownish-yellow marks

2a. Pronotum and scutellum dark brown to black, rarely with few inconspicuous brownish-yellow marks; femora entirely dark brown to black, without brownishyellow rings .......................... T. juazeirensis (Fig. 3) (BA)

$2 b$. Pronotum with $1+1$ elongate or subtriangular broad areas or narrow stripes, brownish-yellow; scutellum with apex of posterior process brownish-yellow; femora with complete or incomplete brownish-yellow rings

TABLE

Measurements (in mm) of Triatoma brasiliensis macromelasoma based on 15 males and 15 females

from a F1 colony reared from insects collected in the type locality (municipality of Petrolina, state of Pernambuco, Brazil)

\begin{tabular}{|c|c|c|c|c|c|c|c|c|c|c|}
\hline \multirow{2}{*}{$\frac{\text { Gender }}{\text { Variables }}$} & \multicolumn{5}{|c|}{ Male } & \multicolumn{5}{|c|}{ Female } \\
\hline & Min & Max & $X$ & $\mathrm{~S}^{2}$ & $\mathrm{SD}$ & Min & Max & $\mathrm{X}$ & $\mathrm{S}^{2}$ & $\mathrm{SD}$ \\
\hline Total length & 19.4 & 24.3 & 21.17 & 1.573 & 1.254 & 21.5 & 25.5 & 23.04 & 0.937 & 0.968 \\
\hline Length of head & 3.7 & 4.7 & 4.19 & 0.001 & 0.027 & 4.1 & 4.8 & 4.40 & 0.000 & 0.018 \\
\hline Width of head & 1.9 & 2.4 & 2.09 & 0.000 & 0.012 & 2.0 & 2.3 & 2.13 & 0.000 & 0.008 \\
\hline Synthlipsis & 1.0 & 1.2 & 1.07 & 0.000 & 0.007 & 1.1 & 1.3 & 1.15 & 0.000 & 0.007 \\
\hline Width of eyes & 0.5 & 0.6 & 0.50 & 0.000 & 0.003 & 0.5 & 0.6 & 0.51 & 0.000 & 0.003 \\
\hline Length of 1st antennal segment & 0.7 & 1.0 & 0.82 & 0.000 & 0.007 & 0.8 & 1.0 & 0.93 & 0.000 & 0.007 \\
\hline Length of 2 nd antennal segment & 3.4 & 4.0 & 3.70 & 0.000 & 0.021 & 3.4 & 4.3 & 3.78 & 0.001 & 0.023 \\
\hline Length of 3rd antennal segment & 2.3 & 2.8 & 2.52 & 0.000 & 0.014 & 2.4 & 2.9 & 2.61 & 0.000 & 0.017 \\
\hline Length of 4 th antennal segment & 1.8 & 2.1 & 1.95 & 0.000 & 0.013 & 2.0 & 2.4 & 2.14 & 0.000 & 0.011 \\
\hline Length of 1 st rostral segment & 0.9 & 1.1 & 0.98 & 0.000 & 0.006 & 1.0 & 1.1 & 1.04 & 0.000 & 0.005 \\
\hline Length of 2 nd rostral segment & 2.1 & 2.4 & 2.24 & 0.000 & 0.010 & 2.2 & 2.5 & 2.28 & 0.000 & 0.009 \\
\hline Length of 3rd rostral segment & 1.0 & 1.2 & 1.15 & 0.000 & 0.006 & 1.1 & 1.4 & 1.20 & 0.000 & 0.006 \\
\hline Length of pronotum & 2.8 & 3.9 & 3.16 & 0.001 & 0.030 & 3.1 & 3.9 & 3.34 & 0.000 & 0.022 \\
\hline Anterior width of pronotum & 2.4 & 3.1 & 2.66 & 0.000 & 0.020 & 2.6 & 3.2 & 2.83 & 0.000 & 0.016 \\
\hline Posterior width of pronotum & 3.9 & 5.4 & 4.39 & 0.001 & 0.037 & 4.4 & 5.3 & 4.69 & 0.001 & 0.027 \\
\hline Width of abdomen & 6.0 & 7.6 & 6.69 & 0.003 & 0.052 & 6.6 & 9.1 & 7.44 & 0.004 & 0.062 \\
\hline
\end{tabular}

Max; maxima; Min: minimum; SD: standard deviation; $\mathrm{S}^{2}$ : variance; X: average. 
3a. Pronotum with $1+1$ narrow brownish-yellow stripes; membrane of hemelytra with lumen of cells partially darkened ........ T. b. macromelasoma (Fig. 1) (PE)

3b. Pronotum with $1+1$ broad, elongated brownishyellow areas; membrane of hemelytra with lumen of cells entirely or not darkened ... 4

4a. Pronotum with $1+1$ brownish-yellow areas extending from posterior portion of anterior lobe to posterior lobe; femora with broad brownish-yellow rings; membrane of hemelytra with lumen of cells not darkened; males with spongy fossulae on fore and mid tibiae ......................... T. b. brasiliensis (Fig. 2) (Northeast Region of Brazil, state of Goiás and Federal District)

4 b. Pronotum with $1+1$ brownish-yellow areas only on posterior lobe; femora with narrow brownish-yellow rings; membrane of hemelytra with lumen of cells entirely darkened; males with spongy fossulae only on fore tibiae T. melanica (Fig. 4) (BA and MG)

\section{DISCUSSION}

Triatoma b. brasiliensis and T. b. macromelasoma are the most closely related forms among all members of the T. brasiliensis complex. This was determined from an isoenzymatic analysis with nine loci conducted to calculate the values of Nei's genetic distance (Nei 1987, Costa et al. 1997b) and the sequences of the mtDNA cytochrome $b$ gene and by applying phylogeographic approaches among 136 specimens representing 16 populations (Monteiro et al. 2004). The latter analysis revealed the existence of three discrete lineages: brasiliensis+macromelasoma, juazeiro (T. juazeirensis) and melanica. These clades are separated from each other by more than nine mutational steps, which is the $95 \%$ confidence interval for the statistical parsimony process.

Despite this close relationship, the phylogenetic analyses showed that $T$. b. brasiliensis and T. b. macromelasoma have significant genetic differentiation, indicating their status as subspecies (Monteiro et al. 2004). In addition, Costa et al. (2009) used geometric morphometric techniques to compare the shape of the wings of the $T$. brasiliensis complex members. These authors proposed that $T$. b. macromelasoma could have originated by homoploid hybrid speciation (Greig et al. 2002, Gross \& Rieseberg 2005, Mavarez et al. 2006, Meyer et al. 2006, Mallet 2007) via ancient contact between the neighbouring species T. brasiliensis and T. juazeirensis and the hybridisation of the putative parental forms most likely occurred in the area of PE. Furthermore, the geometric morphometric analysis showed that T. b. macromelasoma is closely related to T. b. brasiliensis and is distinct from all other members of the $T$. brasiliensis complex (Costa et al. 2009). The Mahalanobis distances were calculated for all members of the complex based on the shape (conformation) of the wings and these were convergent with the values of the matrices of genetic distances obtained either by isoenzyme analyses or mtDNA sequences (Costa et al. 2009). In addition, despite all morphological, biological, genetic and ecological differences recorded among the members of the complex, they are all able to produce viable hybrids under laboratory conditions (Costa et al. 2003b, Almeida et al. 2012). However, no evidence of natural crosses was observed between the members of the complex, except for T. b. brasiliensis and T. $b$. macromelasoma.

These multidisciplinary analyses revealed that $T . b$. macromelasoma has (i) a stable, homogeneous and differentiated colour pattern that is easily distinguished from those of the other members of the complex (Costa et al. 1997a, 2009), (ii) a distinct egg shape and exochorion ornamentation (Costa et al. 1997a) and (iii) a distinct geographic distribution, as it is found only in areas of PE (Costa et al. 1998, 2003a). Therefore, the revalidation of $T$. b. macromelasoma as a subspecies agrees with the results of several independent taxonomic analyses, showing the closest relationship between this taxon and T. b. brasiliensis when compared to the other members of the complex.

Morphologically, T. b. macromelasoma can be distinguished from all members of the T. brasiliensis species complex by the following combination of features: (i) pronotum with $1+1$ narrow brownish-yellow stripes on the submedian carinae, not attaining its apex, (ii) hemelytra with darkened membrane cells on the central portion and (iii) legs with an incomplete brownish-yellow ring on the apical half of the femora. The yellow marks on the pronotum are the more consistent feature that differentiates the members of the complex (Lent \& Wygodzinsky 1979, Costa 1997). As expected, the females of T. b. macromelasoma tend to be slightly larger than the males, a pattern commonly observed in triatomines (Lent \& Wygodzinsky 1979) and, more specifically, in other members of the T. brasiliensis complex (Costa et al. 2006, Costa \& Felix 2007).

A definition of the taxonomic status of the T. brasiliensis complex members is important for epidemiological studies and control measures (Costa \& Felix 2007) and correct morphological identification is equally important. Thus, the present key, which includes all members of the complex, can be considered a fundamental tool for the identification of specimens, especially in fieldwork.

\section{ACKNOWLEDGEMENTS}

To Archibaldo Belo Galvão (in memoriam) and Herman Lent (in memoriam), for suggestions and incentive, and to the technicians of the SVS and Funasa, Brazil, for valuable help in the fieldworks.

\section{REFERENCES}

Almeida CE, Oliveira HL, Correia N, Dornak LL, Gumiel M, Neiva VL, Harry M, Mendonça VJ, Costa J, Galvão C 2012. Dispersion capacity of Triatoma sherlocki, Triatoma juazeirensis and laboratory-bred hybrids. Acta Trop 122: 71-79.

Bérenger JM, Blanchet D 2007. A new species of the genus Panstrongylus from French Guiana (Heteroptera; Reduviidae; Triatominae). Mem Inst Oswaldo Cruz 102: 733-736.

Costa J 1997. Triatoma brasiliensis Neiva, 1911 (Hemiptera: Reduviidae: Triatominae): Estudos morfológicos, biológicos e isoenzimáticos sobre diferentes padrões cromáticos, $\mathrm{PhD}$ Thesis, Instituto Oswaldo Cruz-Fiocruz, Rio de Janeiro, 100 pp.

Costa J, Almeida CE, Dotson EM, Lins A, Vinhaes M, Silveira AC, Beard CB 2003a. The epidemiologic importance of Triatoma brasiliensis as a Chagas disease vector in Brazil: a revision of 
domiciliary captures during 1993-1999. Mem Inst Oswaldo Cruz 98: 443-449.

Costa J, Almeida CE, Dujardin JP, Beard CB 2003b. Crossing experiments detect genetic incompatibility among populations of Triatoma brasiliensis Neiva, 1911 (Heteroptera, Reduviidae, Triatominae). Mem Inst Oswaldo Cruz 98: 637-639.

Costa J, Argolo AM, Felix M 2006. Redescription of Triatoma melanica Neiva \& Lent, 1941, new status (Hemiptera: Reduviidae: Triatominae). Zootaxa 1385: 47-58.

Costa J, Barth OM, Marchon-Silva V, Almeida CE, Freitas-Sibajev MG, Panzera F 1997a. Morphological studies on the Triatoma brasiliensis Neiva, 1911 (Hemiptera, Reduviidae, Triatominae) genital structures and eggs of different chromatic forms. Mem Inst Oswaldo Cruz 92: 493-498.

Costa J, de Almeida JR, Britto C, Duarte R, Marchon-Silva V, Pacheco RS 1998. Ecotopes, natural infection and trophic resources of Triatoma brasiliensis (Hemiptera, Reduviidae, Triatominae). Mem Inst Oswaldo Cruz 93: 7-13.

Costa J, Felix M 2007. Triatoma juazeirensis sp. nov. from the state of Bahia, northeastern Brazil (Hemiptera: Reduviidae: Triatominae). Mem Inst Oswaldo Cruz 102: 87-90.

Costa J, Freitas-Sibajev MGR, Marchon-Silva V, Pires MQ, Pacheco RS 1997b. Isoenzymes detect variation in populations of Triatoma brasiliensis (Hemiptera: Reduviidae: Triatominae). Mem Inst Oswaldo Cruz 92: 459-464.

Costa J, Marchon-Silva V 1998. Período de intermuda e resistência ao jejum de diferentes populações de Triatoma brasiliensis (Hemiptera: Reduviidae: Triatominae). Entomol Vectores 5: 23-34.

Costa J, Peterson AT, Beard CB 2002. Ecologic niche modeling and differentiation of populations of Triatoma brasiliensis Neiva, 1911, the most important Chagas disease vector in Northeastern Brazil (Hemiptera: Reduviidae: Triatominae). Am J Trop Med Hyg 67: 516-520.

Costa J, Peterson AT, Dujardin JP 2009. Morphological evidence suggests homoploid hybridization as a possible mode of speciation in the Triatominae (Hemiptera: Reduviidae: Triatominae). Infect Genet Evol 9: 263-270.

Forero D, Weirauch C, Baena M 2004. Synonymy of the reduviid (Hemiptera: Heteroptera) genus Torrealbaia (Triatominae) with Amphibolus (Harpactorinae), with notes on Amphibolus venator (Klug, 1830). Zootaxa 670: 1-12.

Galvão AB 1956. Triatoma brasiliensis macromelasoma n. subsp. (Reduviidae: Hemiptera). Rev Bras Mal D Trop 7: 455-457.

Galvão C, Angulo VM 2006. Belminus corredori, a new species of Bolboderini (Hemiptera: Reduviidae: Triatominae) from Santander, Colombia. Zootaxa 1241: 61-68.

Galvão C, Carcavallo R, Rocha DS, Jurberg J 2003. A checklist of the current valid species of the subfamily Triatominae Jeannel, 1919 (Hemiptera: Reduviidae) and their geographical distribution with nomenclatural and taxonomic notes. Zootaxa 202: 1-36.

Gonçalves TCM, de Almeida MD, Jurberg J, Lent H 1993. Lista dos exemplares-tipos de triatomíneos depositados na Coleção Entomológica do Instituto Oswaldo Cruz, Rio de Janeiro (Hemiptera: Reduviidae). Mem Inst Oswaldo Cruz 88: 327-333.

Gonçalves TCM, Teves-Neves SC, Santos-Mallet JR, Carbajal-de-laFuente AL, Lopes CM 2013. Triatoma jatai sp. nov. in state of
Tocantins, Brazil (Hemiptera: Reduviidae: Triatominae). Mem Inst Oswaldo Cruz 108: 429-437.

Greig D, Louis EJ, Borts RH, Travisano M 2002. Hybrid speciation in experimental populations of yeast. Science 298: 1773-1775.

Gross BL, Rieseberg LH 2005. The ecological genetics of homoploid hybrid speciation. J Hered 96: 241-252.

Jurberg J, Rocha DS, Galvão C 2009. Rhodnius zeledoni sp. nov. afim de Rhodnius paraensis Sherlock, Guitton \& Miles, 1977 (Hemiptera: Reduviidae: Triatominae). Biota Neotrop 9: 123-128.

Lent H, Jurberg J 1978. Estudo comparativo da genitália externa masculina de seis espécies de Triatoma Laporte, 1832 que mais frequentemente habitam o domicílio humano no Brasil (Hemiptera: Reduviidae). Rev Bras Biol 38: 931-944.

Lent H, Wygodzinsky P 1979. Revision of the Triatominae (Hemiptera: Reduviidae) and their significance as vectors of Chagas disease. Bull Am Mus Nat Hist 163: 125-520.

Mallet J 2007. Hybrid speciation. Nature 446: 279-283.

Martinez E, Chávez T, Sossa D, Aranda R, Vargas B, Vidaurre P 2007. Triatoma boliviana sp. n. de los valles subandinos de La Paz, Bolivia (Hemiptera: Reduviidae: Triatominae) similar a Triatoma nigromaculata Stål, 1859. Bol Inst Invest Salud Desar 3: 1-11.

Mavarez J, Salazar CA, Bermingham E, Christian S, Jiggins CD 2006. Speciation by hybridization in Heliconius butterflies. $\mathrm{Na}$ ture 441: 868-871.

Mendonça VJ, Silva MTA, Araújo RF, Júnior JM, Júnior MB, Almeida CE, Costa J, Graminha MAS, Cicarelli RMB, Rosa JA 2009. Phylogeny of Triatoma sherlocki (Hemiptera: Reduviidae: Triatominae) inferred from two mitochondrial genes suggests its location within the Triatoma brasiliensis complex. Am J Trop Med Hyg 81: 858-864.

Meyer A, Salzburger W, Schartl M 2006. Hybrid origin of a swordtail species (Teleostei: Xiphophorus clemenciae) driven by sexual selection. Mol Ecol 15: 721-730.

Monteiro FA, Donnelly MJ, Beard CB, Costa J 2004. Nested clade and phylogeographic analyses of the Chagas disease vector Triatoma brasiliensis in Northeast Brazil. Mol Phylogenet Evol 32: 46-56.

Nei M 1987. Molecular evolutionary genetics, Columbia University Press, New York, 512 pp.

Poinar Jr G 2005. Triatoma dominicana sp. n. (Hemiptera: Reduviidae: Triatominae), and Trypanosoma antiquus sp. n. (Stercoraria: Trypanosomatidae), the first fossil evidence of a triatomine-trypanosomatid vector association. Vector-Borne Zoonotic Dis 5: 72-81.

Rosa JA, Rocha CS, Gardim S, Pinto MC, Mendonça VJ, Ferreira Filho JCR, Carvalho EOC, Camargo LMA, Oliveira J, Nascimento JD, Cilense M, Almeida CE 2012. Description of Rhodnius montenegrensis $\mathrm{n}$. sp. (Hemiptera: Reduviidae: Triatominae) from the state of Rondônia, Brazil. Zootaxa 3478: 62-76.

Sandoval CM, Pabón E, Jurberg J, Galvão C 2007. Belminus ferroae n. sp. from the Colombian North-East with a key to the species of the genus (Hemiptera: Reduviidae: Triatominae). Zootaxa 1443: 55-64.

Silveira AC, Vinhaes MC 1999. Elimination of vector-borne transmission of Chagas disease. Mem Inst Oswaldo Cruz 94 (Suppl. I): $405-411$. 